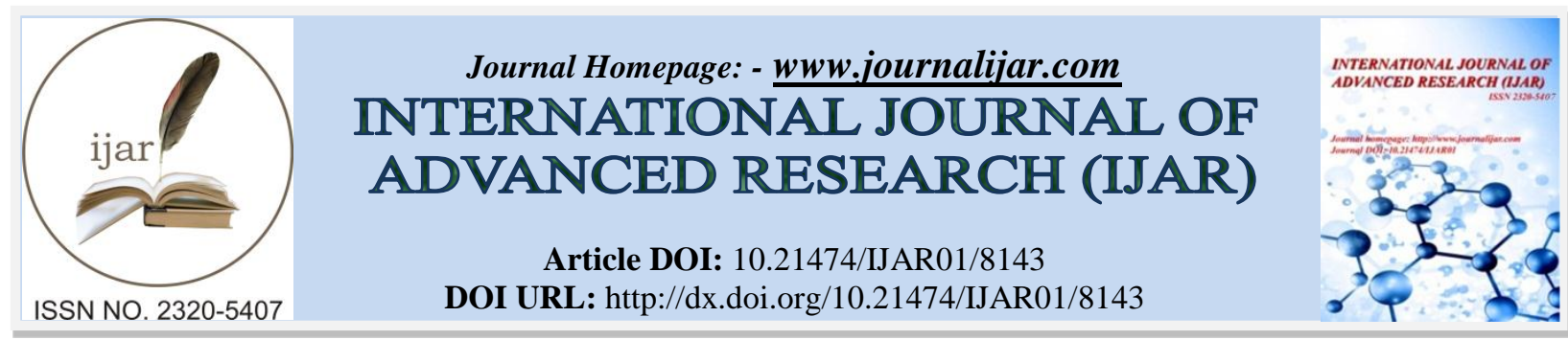

RESEARCH ARTICLE

\title{
IN VIVO PROTECTIVE EFFECT OF NELSONIA CANESCENS (LAM.) SPRENG EXTRACTS AGAINST CARBON TETRACHLORIDE-INDUCED HEPATOTOXICITY IN RATS.
}

\section{Ouattara Nabèrè ${ }^{1}$, Konaté Kiessoun ${ }^{2}$, Meda Nâg-tiero Roland ${ }^{3}$, Guenné Samson ${ }^{4}$, Compaoré Moussa ${ }^{4}$, Ouédraogo Noufou ${ }^{5}$, Hilou Adama ${ }^{4}$, Kiendrébeogo Martin ${ }^{4}$ and Nacoulma Odile Germaine ${ }^{4}$.}

1. Laboratory of Applied Biochemistry and Chemistry, UO I, JKZ/ University of Dédougou, BP 176, Burkina Faso.

2. Laboratory of Food Biochemistry, Enzymology, Biotechnology and Bioinformatic, University of Ouagadougou, 03 P.O.Box: 848, Ouagadougou 03, Burkina Faso.

3. Laboratory for Research and Education in Animal Health and Biotechnology, University of Nazi BONI, 01 BP 1091 Bobo-Dioulasso 01, Burkina Faso.

4. Laboratory of Applied Biochemistry and Chemistry, University of Ouaga I, Professor Joseph KI-ZERBO 03 BP 7021 Ouagadougou 03, Burkina Faso.

5. Department of Traditional Medicine and Pharmacopoeia-Pharmacy / Institute for Research in Health Sciences (MEPHATRA-PH / IRSS), 03 BP 7192 Ouagadougou 03, Burkina Faso.

\section{Manuscript Info}

Manuscript History

Received: 04 October 2018

Final Accepted: 06 November 2018

Published: December 2018

Keywords:

Nelsonia canescens, Hepatoprotective,

Carbon tetrachloride, Serum enzymes.

\section{Abstract}

Objective: To investigate the in vivo protective effect of Nelsonia canescens extracts against carbon tetrachloride-induced hepatotoxicity in rats.

Methods: The anti-hepatotoxicity activity was assessed through toxicity studies, measurement of serum Alanine aminotransferase,Aspartate Aminotransferase levels, evaluation of lipid peroxidation and histological examination.

Results: The findings were that methanolic extract of $N$. canescens exhibited a good anti-hepatoprotoxicity. For the serum Alanine aminotransferase content, the treated batch with the $N$. canescens extract had content $(20.93 \pm 5.90 \mathrm{IU} / \mathrm{L})$ close to silymarin control batch $(17.77 \pm 0.90 \mathrm{IU} / \mathrm{L})$. As regards the Aspartate Aminotransferase content, an interesting result was found with the batch of rats still treated with $N$. canescens extract showed an interesting result $(25.11 \pm$ 4.07 IU/L) quite close to the batch of non-intoxicated rats $(20 \pm 1.51$ IU/L). In addition, pretreatment with $N$. canescens methanolic extract and sylimarin decreased the level of lipid peroxidation which resulted in the decrease of Malondialdehyde level compared to the group without treatment. Regarding the morphological examination of rat liver tissue after treatment with Carbon tetrachloride, a similar tissue healing effectiveness was found with $N$. canescens extract and silymarin, a standard drug used.

Conclusion: The Nelsonia canescens methanolic extract exhibited a good anti-hepatotoxicity capacity. The presence of phenolic compounds identified in this species could mainly responsible for these

Corresponding Author:-Ouattara Nabèrè. 
in vivo biological activities. These results could justify the widely use of this plant species in Burkina Faso traditional medicine for liver disorders.

Copy Right, IJAR, 2018,. All rights reserved.

\section{Introduction:-}

Liver is the most important organ concerned with the biochemical activities in the human body. It regulates many important metabolic functions and hepatic injury is associated with alteration of these metabolic functions (Wolf, 1999). Nowadays, severe liver diseases are one of the most serious health problems in the world and are characterized by a progressive evolution from steatosis to chronic hepatitis, fibrosis, cirrhosis, hepatocellular carcinoma and their prevention and treatment options still remain limited (Pundir R, 2009). Experimentally, Carbon tetrachloride $\left(\mathrm{CCl}_{4}\right)$ is a well-known model compound for producing chemical hepatic injury. It is biotransformed by hepatic microsomal cytochrome $\mathrm{P}_{450}(\mathrm{CYP}) 2 \mathrm{E} 1$ to trichloromethyl-free radicals $\left(\mathrm{CCl}_{3}{ }^{\circ}\right.$ and/or $\mathrm{CCl}_{3} \mathrm{OO}{ }^{\circ}$ ) and generally, these free radicals react with antioxidant enzymes such as glutathione (GSH), catalase and superoxide dismutase (SOD)(Rikans, 1994). It is indeed the overproduction of trichloromethyl-free radicals who is considered that the initial step in a chain of events that eventually lead to membrane lipid peroxidation and finally to cell apoptosis and necrosis (Weber, 2003). Hence, prevention of hepatotoxic damage is of great concern and the majority of these therapies act as free radical hunters. Indeed, medicinal plants used in traditional medicine are true sources of secondary metabolites with undeniable anti-radical properties. Many traditional remedies are used for the treatment of liver ailments.

Nelsonia canescens, a small perennial herb with soft decumbent villous branches (Owoyele, 2005 ) is traditionally used for malaria, cancer, gout, cardiovascular and inflammatory diseases treatments (Hussain, 2010), (Rout, 2009), (Shahin, 2008), (Bah, 2006). In Burkina Faso, the specie is widely used in traditional medicine for the treatment of many diseases including liver disorders(Nacoulma, 1996).

Previous studies on $N$. canescens have reported the in vitro antioxidant and anticancer activities of methanolic extract from whole plant (Ouattara Nabèrè, 2012), in vivo analgesic and anti-inflammatory activities of ethanolic extract from leaves of (Owoyele, 2005 ). N. canescens has shown a good hepatoprotection at a dose of $500 \mathrm{mg} / \mathrm{kg}$ using liver disorders with paracetamol(BEDABATI DASGUPTA, 2012) and carbon tetrachloride (Bedabati Dasgupta, 2011)which was proved in biochemical studies as well as from histopathological studies. Phytochemical investigations by HPLC-MS revealed the presence of five phenol acids (p-coumaric acid, caffeic acid, chlorogenic acid, ferulic acid and gentisic acid) and three flavonoids (apigenin, luteolin, Quercetol) (Nabèrè Ouattara, 2013)

In continuation of these preliminaries studies, the present work was conducted to evaluate the in vivo protective effect of this plant extract using carbon tetrachloride-induced hepatotoxicity models.

\section{Materials and methods:-}

Animals and treatment regimens:-

Male and female Wistar rats weighing $231.78 \pm 39.39 \mathrm{~g}$ from the UFR / SVT pet shop of the University of Ouagadougou, Burkina Faso were used for in vivo testing. The animals were acclimatized for one week $\left(25^{\circ} \mathrm{C}\right.$ with a circadian cycle) in the animal pet shop of the Department of Medicine and Traditional Pharmacopoeia / Pharmacy (MEPHATRA / PH) of IRSS / CNRST of Ouagadougou before any manipulation.

\section{Toxicity studies:-}

The mice were randomized into 6 groups of 6 mice (18 males and 18 females) including a control group. Each animal was identified by a different brand. The animals were pre-fasted for 12 hours, the weight of each mouse was taken, and then have received a given dose of extract of $3000 \mathrm{mg} / \mathrm{kg}\left(\mathrm{w}_{\text {extract }} / \mathrm{w}_{\text {mice }}\right)$. The administration way of the extracts has been either the oral way or the intraperitoneal way(Ouedraogo, 2001). The number of deaths per batch was determined after 2hours, 24hours, 48hours, 72hours and the animals were kept under observation for 14 days.

The method for calculating the $50 \%$ lethal dose $\left(\mathrm{LD}_{50}\right)$ and its confidence limits was described by the method of Miller and Tainter (Miller, 1944). 
Before going to the tests itself, pre-tests were carried out on batches of three (03) animals to locate the lethal dose $50 \%$.

\section{Antihepatotoxicity studies:-}

This antihepatotoxicity activity was evaluated according to the protocol described by (Sanogo, 1998).

The animals were randomly assigned to 4 groups of 6 animals per group. $\mathrm{CCl}_{4}$ was dissolved in olive oil and administered by intraperitoneally injection $(2 \mathrm{~mL} / \mathrm{kg})$.

Group I: normal control group was received daily $10 \mathrm{~mL} / \mathrm{kg}$ of weight of distilled water for 7 days by gavage; the 7 th day the animals were received the olive oil $(2 \mathrm{~mL} / \mathrm{kg}$ of body weight $)$ intraperitoneally 1 hour after the administration of the water;

Group II: negative control group was received $10 \mathrm{~mL} / \mathrm{kg}$ of distilled water per day for 7 days by gavage; the 7 th day the group was received $2 \mathrm{~mL} / \mathrm{kg}$ of $\mathrm{CCl}_{4}(50 \%$ dissolved in olive oil) intraperitoneally 1 hour after the administration of the water;

Group III: positive control group was treated with silymarin (50 mg / kg of body weight) for 7 days by gavage then the 7 th day the animals were received $2 \mathrm{ml} / \mathrm{kg}$ of $\mathrm{CCl}_{4}(50 \%$ dissolved in olive oil $)$ intraperitoneally 1 hour after the administration of the extract.

Group IV: Extract control group was treated with Nelsonia canescens methanol extract (100 mg/Kg of body weight) for 7 days by gavage then the 7 th day the animals were received $2 \mathrm{ml} / \mathrm{kg}$ of $\mathrm{CCl}_{4}(50 \%$ dissolved in olive oil) intraperitoneally 1 hour after the administration of the extract.

\section{Biological analyzes:-}

The animals are weighed throughout the experimental process (for 8 days) and at the 8th day a ketamine anesthesia (150 mg/kg weight) was carried out on the animals in order to collect blood and liver for biochemical and histopathological analyzes respectively.

\section{Measurement of serum ALT, AST levels and evaluation of lipid peroxidation:-}

The blood of the animals was first collected by cardiac puncture in dry tubes, centrifuged at $3000 \mathrm{rpm}$ during 5 minutes and the serum was taken to evaluate the enzymatic parameters related to hepatic necrosis: Aspartate Aminotransferase (AST/GOT) and Alanine aminotransferase (ALT/GPT) using kits (Cypress Diagnostics).

After that the liver of the treated animals was removed and a portion of this organ is ground in (10\% w/v) Tris- $\mathrm{HCl}$ buffer $(50 \mathrm{Mm}, \mathrm{pH}=7.40)$, centrifuged at $6000 \mathrm{rpm}$ for $10 \mathrm{~min}$ and the supernatant was used to evaluate lipid peroxidation (Alqasoumi, 2012).

\section{Histological examination:-}

Portions (about $0.2 \times 0.2 \mathrm{~cm}$ ) of liver were removed and fixed in $10 \%$ formalin solution (Abdel-Kader, 2008). They were then dehydrated in solutions by increasing the ethanol concentration (70 to 100\%) for 2 hours, cleaned in 2 xylene baths, paraffinized in 2 paraffin baths and transferred to paraffin-filled molds. The slices (or sections) of paraffinized livers were made using a rotating microtome (Leitz 1512) were placed on clean microscope slides and stained with Mayer's hematoxylin solution for $15 \mathrm{~min}$. After washing with water and $80 \%$ alcohol and mounting in eosin-phloxine solution, the preparation is finally examined under an optical microscope and photographed.

\section{Statistical analysis:-}

The data were expressed as Mean \pm Standard deviation (SD) of three determinations. Statistical analysis (ANOVA with a statistical significance level set at $\mathrm{p}<0.05$ and linear regression) was carried out with XLSTAT 7.1

\section{Results:-}

Acute toxicity study:-

After 2 hours, 24 hours, 48 hours and 72 hours of administration, no abnormal behavior was observed in rats treated with $N$. canescens extract at doses up to $3000 \mathrm{mg} / \mathrm{kg}$ and $2000 \mathrm{mg} / \mathrm{kg}$ by oral way and intraperitoneal way, respectively. No mortality was also observed during 14days after treatment. 
A similar result is obtained in 2012 by Dasgupta \& col., with a dose up to $3000 \mathrm{~g} / \mathrm{kg}$ body weight of rats(BEDABATI DASGUPTA, 2012).

Antihepatotoxicity evaluation:-

Effect of Antihepatotoxicity studieson body weight:-

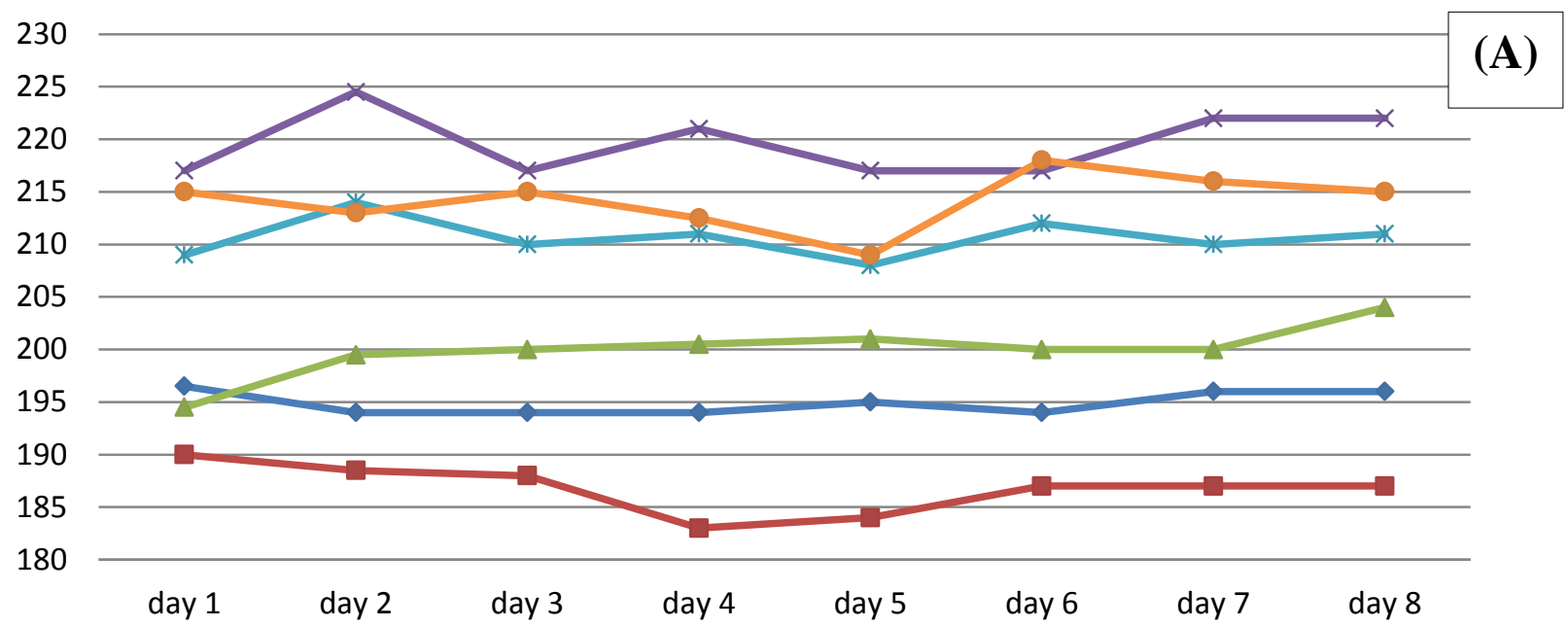

$\sim$ mouse $1 \multimap$ mouse $2 \multimap$ mouse $3 \leftarrow$ mouse $4 \div$ mouse $5 \multimap$ mouse 6

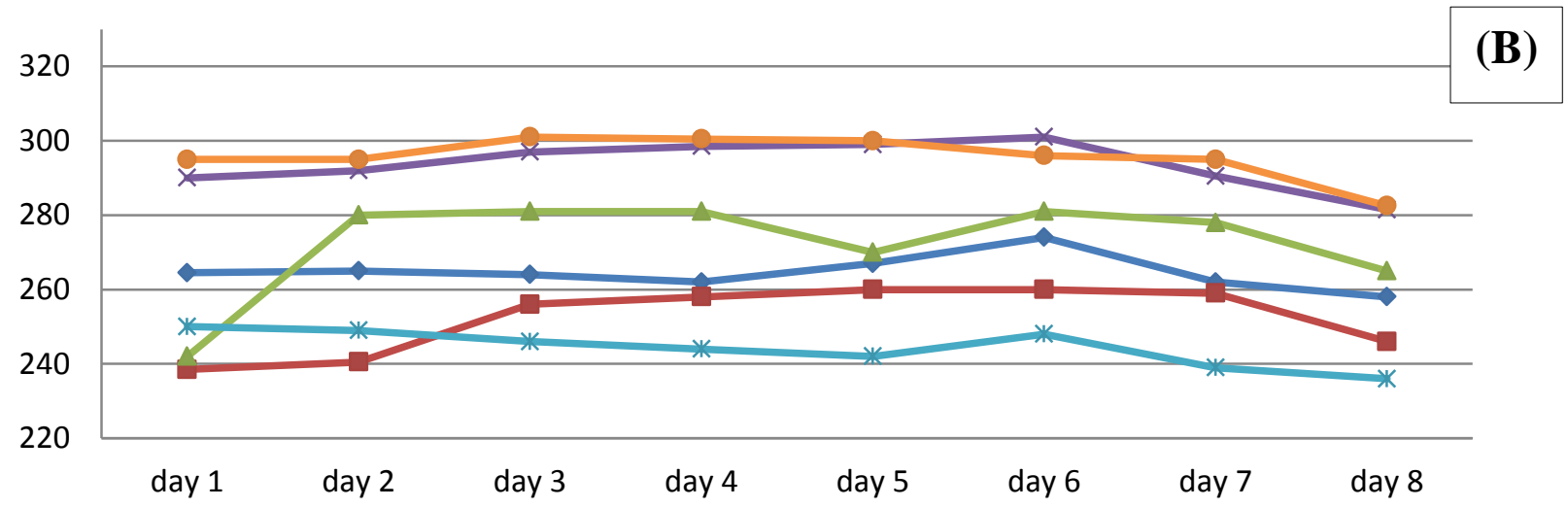

$\neg$ mouse $1 \multimap$ mouse $2 \multimap$ mouse $3 \leftarrow$ mouse $4 \div$ mouse $5 \multimap$ mouse 6 

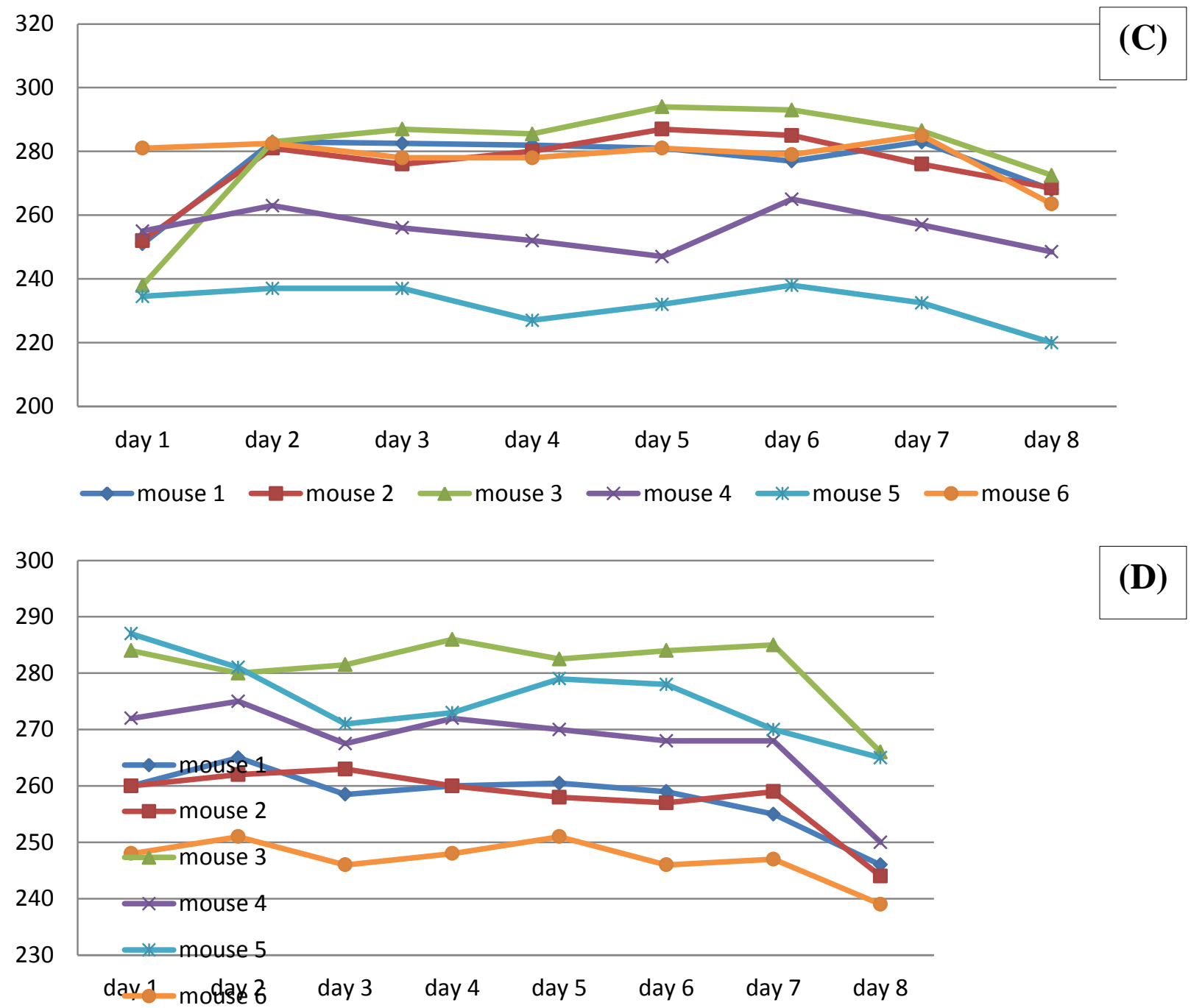

Fig. 1:-Effect of Antihepatotoxicity studies on body weight

(A) Normal control group treated with distilled water during all the experience;

(B) Negative control group treated with distilled water during the experience and receives $\mathrm{CCl}_{4}$ the last day;

(C) Positive control group treated with silymarin during the experience and receives $\mathrm{CCl}_{4}$ the last day;

(D) Extract control group treated with Nelsonia canescens methanol extract during the experience and receives $\mathrm{CCl}_{4}$ the last day.

It appears from this analysis that the weight of the animals is almost invariable until the seventh day of the experiment. Then a remarkable decrease in their weight is observed following the administration of $\mathrm{CCl}_{4}$. This can be explained by the fact that $\mathrm{CCl}_{4}$ induces stress by creating liver lesions and as a result the liver can no longer correctly perform its metabolic functions. These results are indicative evidence of intoxication as, according to some previous studies, weight is a simple and sensitive index of toxicity after exposure to toxic substances (Teo, 2002).

\section{Biochemical changes:-}

The hepatic enzymes of serum ALT and AST are well known as biomarkers for early acute hepatic damage. The effects of pre-treatment with $N$. canescens extracts $(100 \mathrm{mg} / \mathrm{Kg}$ of body weight) and sylimarin $(50 \mathrm{mg} / \mathrm{kg}$ of body weight) on the $\mathrm{CCl}_{4}$-induced elevation of ALT and AST are shown in Fig.2. After data analysis, it's demonstrated that $\mathrm{CCl}_{4}(2 \mathrm{ml} / \mathrm{kg})$ intoxication has developed a severe hepatic damage with a significant increase of serum ALT and AST level ( $\mathrm{p}<0.05)$ compared to the normal control group. For the serum ALT content, the batch of rats treated with the $N$. canescens extract had content $(20.93 \pm 5.90 \mathrm{IU} / \mathrm{L})$ close to that obtained with the batch of rats treated 
with the compound of reference (silymarin) which is $17.77 \pm 0.90 \mathrm{IU} / \mathrm{L}$. As regards the AST content, the batch of rats still treated with $N$. canescens extract showed an interesting result $(25.11 \pm 4.07 \mathrm{IU} / \mathrm{L})$ quite close to the batch of non-intoxicated rats $(20 \pm 1.51 \mathrm{IU} / \mathrm{L})$.

The Malondialdehyde (MDA) level was significantly increase in the rats stressed with the $\mathrm{CCl}_{4}$ compared to the healthy rats $(\mathrm{P}<0.05)$. However, pre-treatment with $N$. canescens extracts and sylimarin decreased the level of lipid peroxidation which resulted in the decrease of MDA level compared to the group without treatment (Fig.3).

In this logic, it's noted that a good hepatoprotection activity is correlated with a better inhibition of lipid peroxidation. This finding could confirm the hypothesis that one of the main causes of $\mathrm{CCl}_{4}$-induced liver injury is lipid peroxidation due to free radicals derived from $\mathrm{CCl}_{4}$.

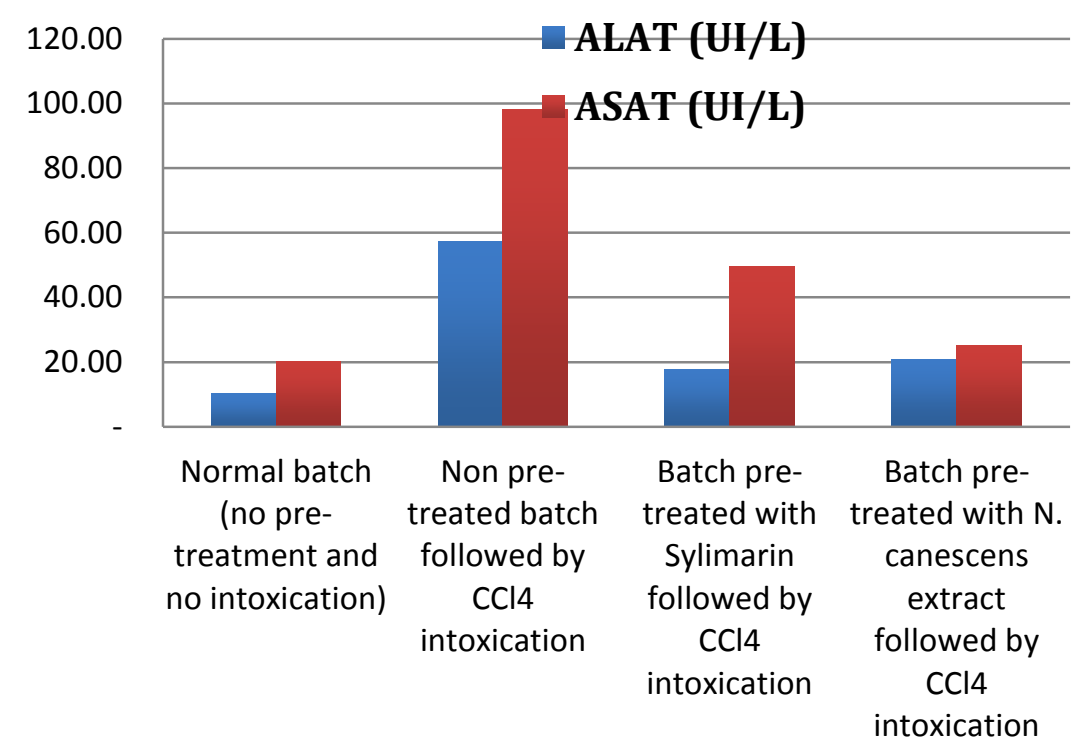

Fig. 2:-Results of serum ALT and AST levels

\section{LPO (mmol of MDA/g)}

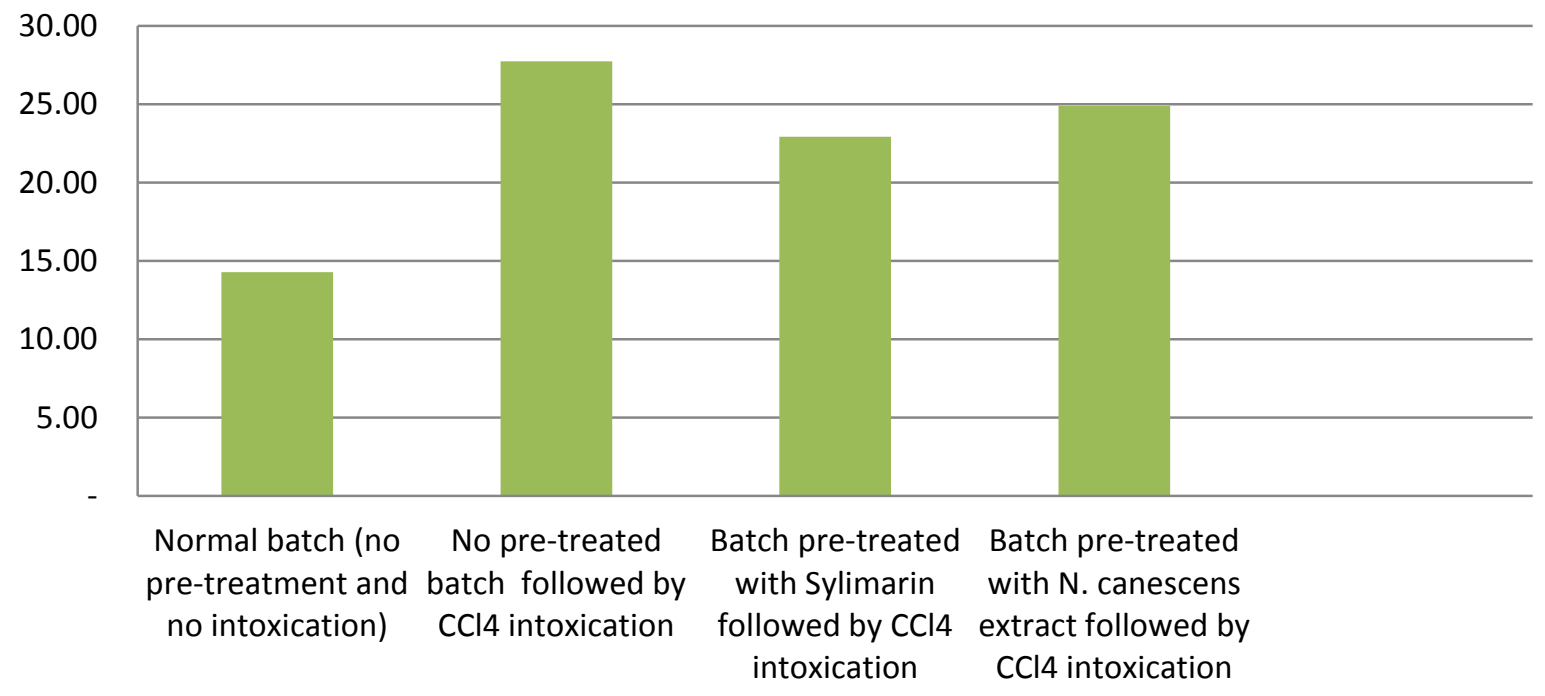




\section{Fig.3. Results of MDA levels (antilipid peroxidation)}

The effect of $N$. canescens extract on histopathology of liver tissue:-

Morphological examination of rat liver tissue showed the visible pale, gross, and irregular surface suggesting the severe hepatocellular damage in $\mathrm{CCl}_{4}$-treated rats (Fig.4 B) as compared to normal control group(Fig.4 A). Pretreatment with $N$. canescens extract (Fig.4 D) as well as pretreatment with silymarin (Fig.4 C)somewhat have protected the liver from $\mathrm{CCl}_{4}$-induced injuries.

The hepatoprotective effect of $N$. canescens extract on $\mathrm{CCl}_{4}$-induced liver damage was further confirmed by histopathological examinations. The liver samples administered with only $\mathrm{CCl}_{4}$ indicated damages such as the cells vacuolization and more necrosis cells. However, in the groups administered with $N$. canescens extract, less percentages of necrosis were observed. Moreover, a similar tissue healing effectiveness was found with $N$. canescens extract and silymarin, a standard drug used.

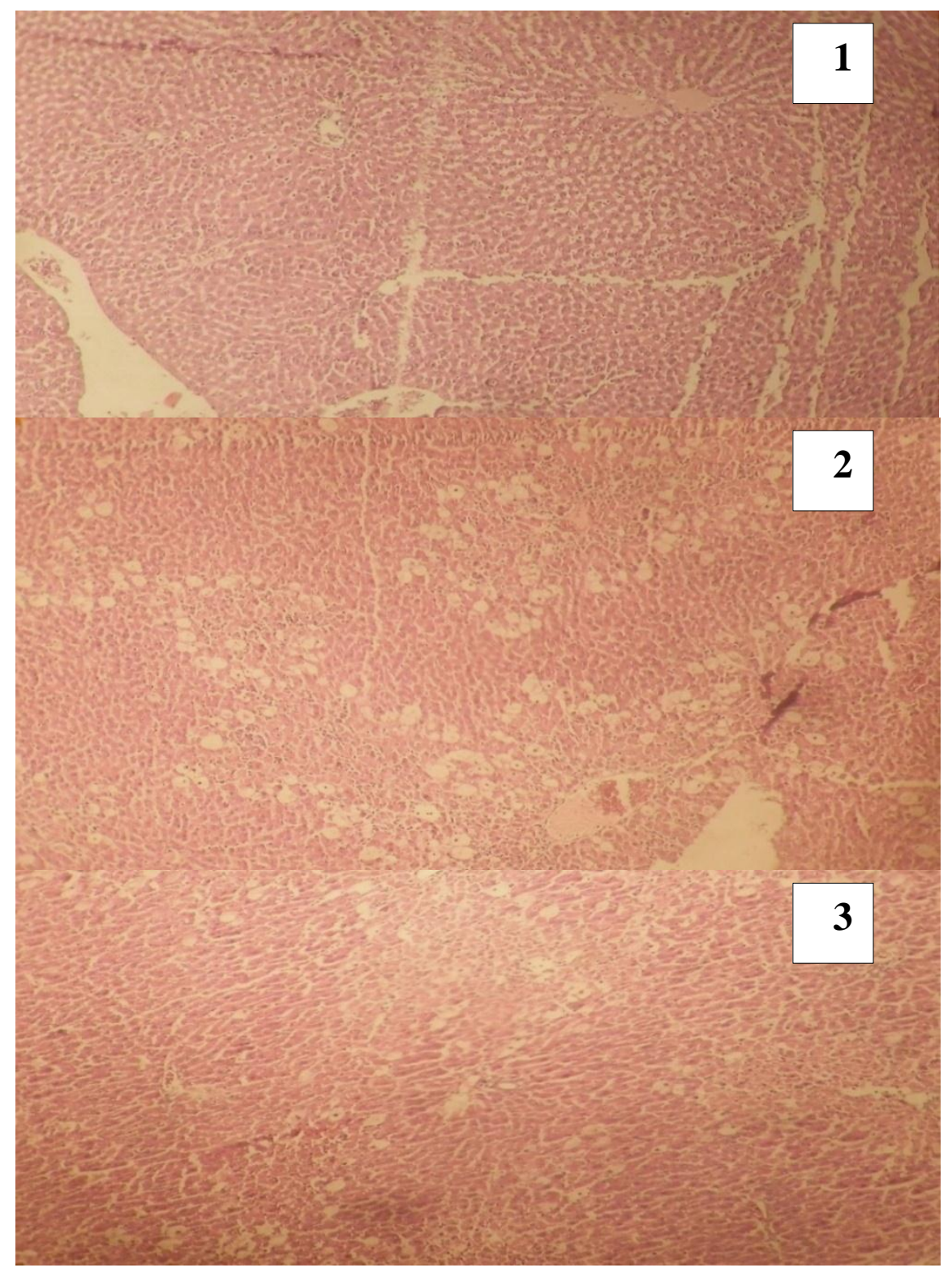




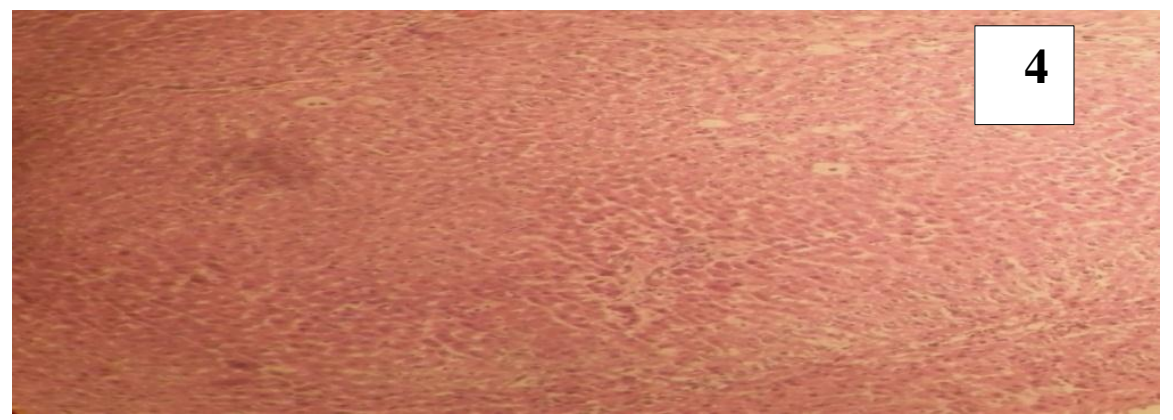

Fig. 4:-Results of protective effect of N. canescens extract on liver tissue

1. Rat liver tissue of normal batch (no pre-treatment and no intoxication);

2. Rat liver tissue of non-pre-treated batch followed by $\mathrm{CCl}_{4}$ intoxication;

3. Rat liver tissue of batch pre-treated with Sylimarin followed by $\mathrm{CCl}_{4}$ intoxication;

4. Rat liver tissue of batch pre-treated with $\mathrm{N}$. canescens extract followed by $\mathrm{CCl}_{4}$ intoxication

\section{Discussion:-}

Numerous medicinal plants exhibit some beneficial effects against various types of degenerative diseases in humans. These effects are largely attributed to the major molecules with an antioxidant activity potentiality. In the present study, the ability of $N$. canescens extract to protect against $\mathrm{CCl}_{4}$-induced hepatotoxicity in rats was investigated. Liver injury is very linked by the level of serum enzymes like AST, ALT. An increasing level of serum AST and ALT by $\mathrm{CCl}_{4}$ have been attributed to hepatic structural damage because these enzymes are normally localized to the cytoplasm and are released into the circulation after cellular damage has occurred(Recknagel, 1989). The present study showed that pretreatment with $N$. canescens extract present a good protection against $\mathrm{CCl}_{4}$-induced hepatic injury.

Previous HPLC-MS study on methanolic extract of this plant species showed numerous compounds: apigenin, luteolin, quercetol, p-coumaric acid, caffeic acid, chlorogenic acid, ferulic acid and gentisic acid(Nabèrè Ouattara, 2013). All this molecules are known for their benefic effect on liver protection. Apigenin, a flavonoid derivative, is reported to possess hepatoprotective properties(A.R. Tapas, 2008). The hepatoprotective effect of luteolin against $\mathrm{CCl}_{4}$ hepatotoxicity on mice was demonstrated. The great defending of quercetin in against hepatic dysfunctions has been revealed(Sun, 2015). Previous studies are demonstrated that p-coumaric acid decreases low density lipoprotein peroxidation and possesses a potential protection on cardiac oxidative damage induced by doxorubicin, an anticancer antibiotic. The caffeic acid has been reported to possess hepatoprotective properties(K.H. Janbaz, 2004); The protective effects on oxidative stress in vivo of chlorogenic acid have been reported(Tsuchiya T, 1996). Ferulic acid prevents $\mathrm{CCl}$-induced hepatotoxicity by suppression of oxidative stress and inflammatory signaling pathways(H-Y. Kim, 2011) and its showed that gentisic acid, an aspirin metabolite, inhibits potently low density lipoprotein oxidation in vitro.

The hepatoprotective effects of $N$. canescens methanolic extract against CCl4-induced hepatic damage in rat could be justify by the presence of these phenolic compounds. In addition, all these different molecules could act synergistically in liver protection.

\section{Conclusion:-}

The present study demonstrates that $N$. canescens methanolic extract has potent hepatoprotective effects against $\mathrm{CCl}_{4}$-induced hepatic damage in rat. This hepatoprotective effects could be associated to the presence of many molecules with their ability to scavenge free radicals and which are previously detected in this plant species. These finding could justify the widely use of this plant species in Burkina Faso traditional medicine to manage the liver disorders. $N$. canescens is an important plant, which could be explored for the production of hepatoprotective drugs.

\section{Conflict of interest statement:-}

We declare that we have no conflict of interest.

In memory of: Dr André TIBIRI 


\section{Acknowledgements:-}

The authors are grateful for Burkina Faso State PhD grant No. 00V242. We are also grateful to the Institute of Research in Health Science (IRSS) for providing any facilities for the in vivo experiences.

\section{References:-}

1. A.r. Tapas, d. M. S., r.b. Kakde 2008. Flavonoids as nutraceuticals: a reviewtrop. J. Pharm. Res. , 7 1089-1099.

2. Abdel-kader, m. S. A., s.i. 2008. Evaluation of the hepatoprotective effect of the ethanol extracts of solanum nigram, cassia fistula, balanites aegyptiaca and cathamus tinctorius against experimentally induced liver injury in rats. Alexandria journal of pharmaceutical sciences, 22, 47-50.

3. Alqasoumi, s. I. 2012. Ameliorative effect of 10-gingerol on drug induced hepatotoxicity in albino rats. . Journal of medicinal plants research, 6 1548-1555.

4. Bah, s., diallo, d., dembélé, s., paulsen, b.s. 2006. Ethnopharmacological survey of plants used for the treatment of shistosomiasis in nioro district, mali. Journal of ethnopharmacology 105, 387-399.

5. Bedabati dasgupta, j. C. K., arudyuti chowdhury and jibon kotoky 2012. Hepatoprotective activity of nelsonia canescens (lam.) Spreng on acute

6. Hepatotoxicity induced by paracetamol international journal of pharmacy and pharmaceutical sciences vol 4 107-112.

7. Bedabati dasgupta, j. C. K., jibon kotoky and arudyuti chowdhury 2011. Hepatoprotective activity of the methanolic extract of nelsonia canescens (lam..) Spreng on carbon tetrachloride induced hepatic damage in albino rats international journal of pharmaceutical sciences review and research volume 8, 35-39.

8. H-y. Kim, j. P., k-h. Lee, d-u. Lee, j-h. Kwak,y. S. Kim, s-m. Lee 2011. Ferulic acid protects against carbon tetrachloride-induced liver injury in mice. Toxicology 282, 104-111.

9. Hussain, m. S. F., s., ali, m. 2010. Hygrophila auriculata (k. Schum) heine: ethnobotany, phytochemistry and pharmacology. . Asian journal of traditional medicines, 5 . 122-131.

10. K.h. Janbaz, s. A. S., a.h. Gilani, 2004. Studies on the protective e ff ects of ca ff eic acid and quercetin on chemical-induced hepatotoxicity in rodents phytomedicine 11 424-430.

11. Miller, 1. C. T., m.l. 1944. Estimation of d150 and its error by means of logarithmic probit paper. . Proc.soc.exp. Biol. Med., 57, 261-264.

12. Nabèrè ouattara, r. N.-t. M., adama hilou, samson guenné, kiessoum konaté, ahmed y coulibaly, martin kiendrébeogo, jeanne f millogo, odile g nacoulma 2013. Anti-acetylcholinesterase and antioxidant activities and hplc-ms analysis of polyphenol from extracts of nelsonia canescens (lam.) Spreng. Asian pacific journal of tropical disease 3,382-388.

13. Nacoulma, o. 1996. Plantes médicinales et pratiques médicales traditionnelles au burkina faso .cas du plateau central .tome i \& ii. Thèse d'etat, univ. Ouaga., 320p et 260p.

14. Ouattara nabèrè, g. S., hilou adama, compaoré moussa, nacoulma p. Aminata, sombié p.a.d. Eric, millogorasolodimby jeanne, nacoulma odile germaine 2012. Antioxidant and anticancer activities of polyphenolic compounds from three acanthaceae medicinal species from burkina faso. International journal of phytomedicine $4552-557$.

15. Ouedraogo, y., nacoulma, o., guissou i.p. \& guede gulna, f. 2001. Evaluation in vivo et in vitro de la toxicite des extraits aqueux d'ecorces de tige et de racines de mitragyna inermis (wilid).o.ktz (rubiaceae). . Pharm. Méd. Trad. Afr. , 11, 13-29.

16. Owoyele, v. B., oloriegbe, y.y., balogun, e.a. \& soladoye, a.o. 2005 analgegic and anti-inflammatory properties of nelsonia canescens leaf extract.. Journal of ethnopharmacology, 99, 153-156.

17. Pundir r, s. G., pandey aa, saraf sa. 2009. Demand of herbal hepatoprotective formulations in lucknow e a survey. Pharm res, 1, 23-33.

18. Recknagel, r. O., glende jr., e.a., dolak, j.a., waller, r.l.,. 1989. Mechanisms of carbon tetrachloride toxicity. Pharmacol. Ther., 43, 139-154.

19. Rikans, 1. E., hornbrook, k.r., cai, y. 1994. Carbon tetrachloride hepatotoxicity as a function of age in female fischer 344 rats. Mech. Ageing. Dev. , 76, 89-99.

20. Rout, s. D., panda, t. \& mishra, n. 2009. Ethno-medicinal plants used to cure different diseases by tribals of mayurbhanj district of north orissa. Ethno-med., 3 27-32.

21. Sanogo, r., germano, m. P., angelo, v. D', guglielmo, m. And de pasquale, r. 1998. Antihepatotoxic properties of entada africana (mimosaceae). Phytotherapy research, 12, s157-s159.

22. Shahin, s. A., naresh, k., abhinav, 1., angad, s., hallihosur, s., abhishek, s. \& utpal, b. 2008. Indian medicinal herbs as sources of antioxidants. . Food research international, 41, 1-15. 
23. Sun, x., yamasaki, m., katsube, t., shiwaku, k.. 2015. Effects of quercetin derivatives from mulberry leaves: improved gene expression related hepatic lipid andglucose metabolism in short-term high-fat fed mice. Nutr. Res. Pract. , 9, 137-143.

24. Teo, s., stirling, d., thomas, s., hoberman, a., kiorpes, a., khetani, v. 2002. A 90-day oral gavage toxicity study of d-methylphenidate and d l-methylphenidate in sprague-dawley rats. . Toxicology 179, 183-196.

25. Tsuchiya t, s. O., igarashi k. 1996. Protective effects of chlorogenic acid on paraquat-induced oxidative stress in rats. Biosci biotechnol biochem 60 765-768.

26. Weber, 1. W., boll, m., stampfl, a. 2003. Hepatotoxicity and mechanism of action of haloalkanes: carbon tetrachloride as a toxicological model crit. Rev. Toxicol., 33, 105-136.

27. Wolf, p. L. 1999. Biochemical diagnosis of liver disease. Iindian journal of clinical biochemistry, 14, 59-90. 